\title{
A Power-Based Model of a Heating Station for District Heating (DH) System Applications
}

\author{
Abdulrahman Dahash Annette Steingrube Mehmet Elci \\ Fraunhofer-Institute for Solar Energy Systems, Heidenhofstraße 2, 79110 Freiburg im Breisgau, Germany \\ \{adahash, asteingr, melci\}@ise.fraunhofer.de
}

\begin{abstract}
District Heating (DH) systems are often seen as a good practical approach to meet the local heat demand of the districts due to its ability to provide affordable and low carbon energy to the consumers. Yet, under today's regulations to renovate the buildings into more energyefficient ones, the local heat demand is decreasing. Therefore, the operation of DH systems is also affected by the changing heat demand profile, which might lead to less profit for the operators of DH systems. Thus, the operators of DH systems strive for an optimal operation at which the heat demand is met and the profits are maximized. Due to the fact that these systems are complex-physical systems, therefore it is difficult to conduct any experimental investigation on them in order to examine the optimal operation. Accordingly, it is crucial to create fundamental models to investigate the optimal operation of such systems. In this paper, a power-based model is built to represent the heating station as part of a DH system. Then, the model is validated using real data from an existing heating station in Freiburg, Germany. The validation results reveal that the goodness-of-fit for the model is held to be good enough to test it for operational optimization cases.
\end{abstract}

Keywords: Modelica, Dymola, Dynamic Modeling, Heating Station, District Heating System, Power-Based Model, Optimization.

\section{Introduction}

District heating (DH) is considered a promising technology to improve the energy efficiency of the space heating systems in buildings (i.e. residential, commercial and industrial) (Olsthoorn et al., 2016). Thus, a greater interest in installing DH systems has arisen in many countries such as European countries, China and Russia. (Jie et al., 2015). DH systems have many advantages, for instance, an optimum use of fuel and thereby limitation of pollution (Benonysson et al., 1995).

Generally, a DH system is represented by transmission networks employed to supply heat from supply side (i.e. generation site) directly and/or indirectly to demand side (i.e. end users) to meet their space heating and domestic hot water (DHW) demand as shown in Figure 1.

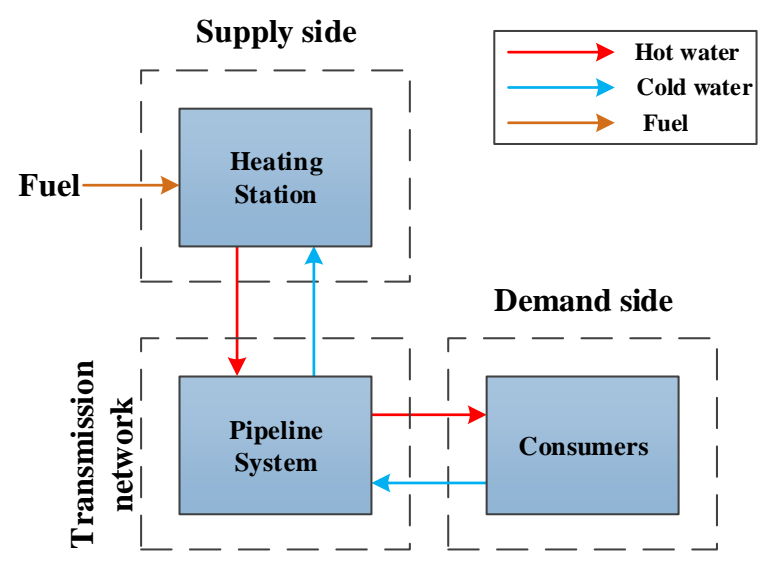

Figure 1: Generic block diagram of a district heating system

Often, DH can be coupled either with centralized heating stations and/or distributed heating units. Thus, numerous kinds of heat generation technologies (boilers, cogeneration plants, heat pumps, etc.) and energy sources (fossil fuels, renewable energies, etc.) can be adopted (Joelsson et al., 2008).

In Germany, combined heat and power (CHP) based DH systems are often seen as a key solution to meet the local heat demand in buildings and, therefore, these CHP units are frequently heat-driven (Elci et al., 2015). This operation mode compared to electricitydriven mode is often seen as the most economical and ecological option and therefore preferred by most operators of distributed energy systems due to the utilization of produced heat to meet the local heat demand and, therefore, no heat is wasted (Shipley et al., 2008) (Bracco et al., 2013). While the produced heat is utilized, the generated electricity is fed into the national power grid either at a fixed tariff, or at a variable tariff that is depending on the electricity price at the European Energy Exchange (EEX). However, because of the refurbishment of buildings to be more energy-efficient, there is a significant change in the heat demand profile of the buildings. Accordingly, this changing profile of the heat demand has a major impact on the operation of CHP units in DH system, 
creating the first challenge in this field by disrupting the viable heat-driven regime mode.

Moreover, a CHP-based DH system can help the power grid to work smoothly by generating electricity when the renewables share in the grid is low due to calm-dark weather (e.g. low solar irradiation) (Kelly et al., 2009). Thus, another challenge has arisen in the field of DH systems, especially in cases when the heat demand is low in the buildings, the storage system is full and it is necessary to operate the heating station to overcome the fluctuations from renewables.

Considering these challenges (continuous changing heat demand and renewables fluctuations), the performance of DH systems (CHP-based) in different operation regimes has to be examined, in order to achieve optimal operation in which the system responds quickly to deviations in electricity prices and distributes the load among the heat sources in the system, so that the highest possible financial gain is achieved while simultaneously the heat demand is fully met. It is surely challenging to achieve this optimization unless fundamental models are built to help in investigating the performance of energy systems under different circumstances.

In this paper, the authors present an approach for modeling of heating stations for DH system applications. The presented model is a power-based model and, therefore, it shows the amount of energy flow between the different generation technologies in the heating station (supply side). The advantages of this modeling approach are less simulation time, better understanding of the energy flow influence on the heating station's operation and assistance in developing power-based control strategies for achieving optimal operation. Whereas the limitation is that the thermohydraulic aspects (e.g. pressure, flow rates) are neglected.

\section{Methodology}

\subsection{Case Study}

As case study, a district in the city of Freiburg in the south of Germany was used. This district is called (Weingarten) and was built in the 1960s and has 9,000 inhabitants. The western part of Weingarten has a population of 5,800 and an area of $0.3 \mathrm{~km}^{2}$, with a gross floor area of about $271,240 \mathrm{~m}^{2}$. The gross floor area comprises: 16-floor residential tower block buildings, 8-floor and 4-floor blocks of flats and nonresidential buildings. Under current regulations regarding comfort, energy efficiency and modern building technology, the buildings in the western part have to be renovated to match current requirements.
This refurbishment works contains modernizing the district's buildings, renew Weingarten's energy supply system and operate it optimally. Figure 2 shows a site plan about the refurbishment area in Weingarten district in which the red colored buildings are the targeted buildings for refurbishment.

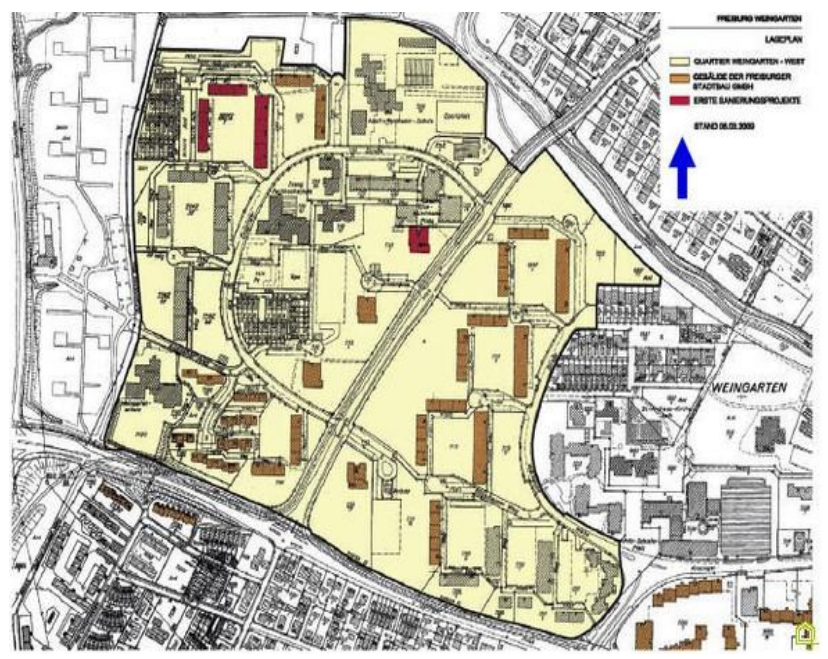

Figure 2: Site plan of the refurbishment area: the planned to be renovated buildings are colored red (Foschung für die Energieeffiziente Stadt, 2016)

The heat supply is delivered by a central heating station that supplies heat to two districts (i.e. Rieselfeld, Weingarten) via a DH network as shown in Figure 3 below. In the heating station, the annual heat generation is $67,400 \mathrm{MWh} / \mathrm{a}$, and maximum heat output is $26,000 \mathrm{~kW}$ and, therefore, 6 gas-fired CHP units are installed and the operation of them is mainly heat-driven. Consequently, two CHP units are operating almost continuously year-round to meet the baseload. The six CHP units produce a total electrical power of $7,200 \mathrm{~kW}_{\mathrm{el}}$ and a heat output of approximately $9,600 \mathrm{~kW}_{\text {th }}$. The CHP modules attain an average of 5,650 full load hours yearly. Hence, over 75 $\%$ of the annual amount of heat produced comes from CHP units, while the remainder is generated by peak boilers. Also, in order to achieve smooth operation of the CHP units, there are two heat storage systems with a total capacity of $360 \mathrm{~m}^{3}$. They help in meeting the demand over short periods. Additionally, three gasfired boilers each with 9.3 MW are employed for peak loads.

Due to the fact that CHP units can produce both heat and electricity, the electricity from the six CHP units is fed into the power grid while the heat produced is used to cover the heat demand. 


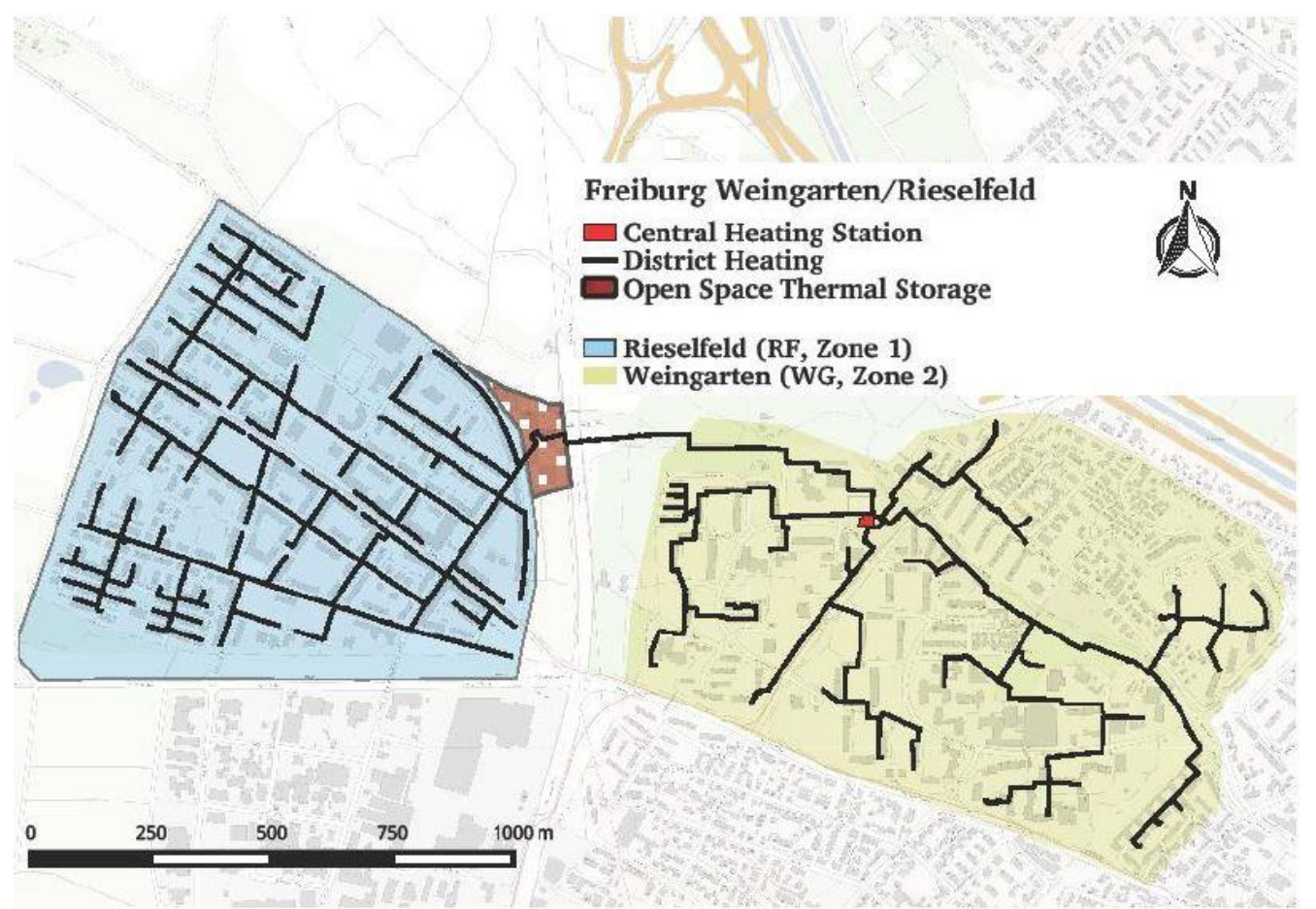

Figure 3: Top view of the Weingarten and Rieselfeld district with the central heating station and DH network

(Bachmaier et al., 2015)

\subsection{Modeling of the Heating Station}

The model represents the real heating station in which an equivalent boiler component is used to represent the three peak boilers. Also, the CHP units are modeled to show the amount of energy flow while the storage system is modeled as stratification water storage. The modeling allows the different temperature segments to be shown within the storage system. In this work, the Modelica standard library (MSL) for basic components (e.g. prescribed heat flow, sensors and etc.), while buildings library is used for thermohydraulic components (e.g. flow sources/sinks, storage etc.).

\subsubsection{Consumer}

This component represents the demand side to which the heat shall be supplied. Therefore, it has two ports, one of which is an output signal for heat demand and the other an input signal for heat supply. The Consumer component is afterwards connected with the first controller in the heating station ( $1^{s t} \mathrm{CHP}$ controller) and is backwards connected with the heat supply collectors using the different technologies. Also, the heat demand profile is read from a text file that is implemented in component (Heat_Demand_Profile) as seen in the left part of Figure 4.

This component plays a major role in the instant energy balance. For example, if the heat demand is higher than the heat supply it signals negative energy flow as seen in the gain component in Figure 4. Then the signal is translated in order to operate the heating station and therefore:

$$
\dot{Q}_{\text {demand }}=\dot{Q}_{\text {Supply }}
$$

Also, Figure 4 shows that there is a water source (a pump) implemented in the consumer model, the function of this component is to provide water with a predefined mass flowrate and temperature. Then the supplied water gets a signal of the required heat demand with a negative sign and a signal of the supplied heat simultaneously in order to inspect the energy balance and to fulfill it.

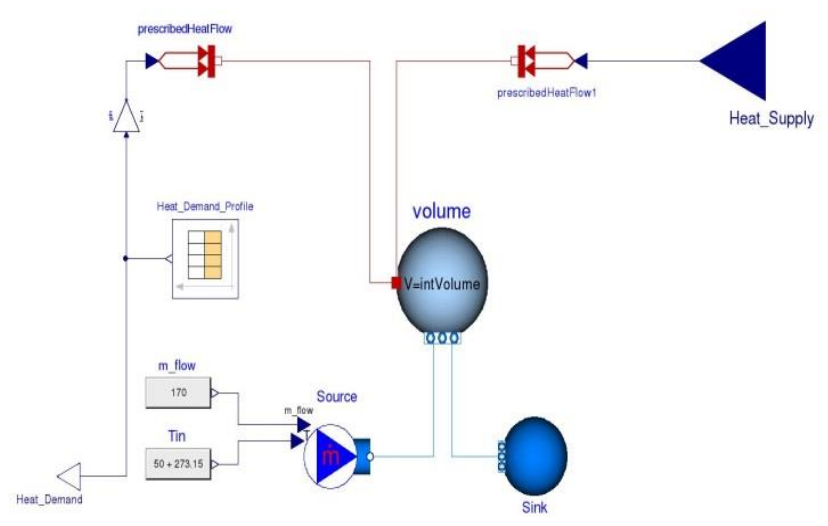

Figure 4: Structure of consumer component

\subsubsection{Heat Sources}

\subsubsection{CHP unit}

The CHP unit has a Boolean input that works as an on/off button, and an output that gives the amount of heat produced by this unit. 
For the sake of simplicity in the modeling of CHP units, the following assumptions are made:

1. The response time of the components is included in the model. In reality, all the mechanical or electrical equipment has a certain response time (Smit, 2006). However, in this model, the response time is approximated to 1800 seconds for the entire CHP and it is given in the delay component that receives and sends Boolean signals as shown in Figure 5.

2. CHP units do not run at partial loads, they run only at full loads. When the CHP units run at partial loads, the thermal and electrical efficiency of the CHP units are different than the nominal values. Hence, only full load operation is considered as it is also valid in the actual system, Weingarten heating station.

$\dot{Q}_{\mathrm{CHP}}=\left\{\begin{array}{c}1.5 \mathrm{MW} \\ 0\end{array}\right.$

3. The system is not modeled as a closed loop, meaning that the supply and return temperature of the water or steam in the system is not controlled. This assumption is made to reduce the run time of the simulation.

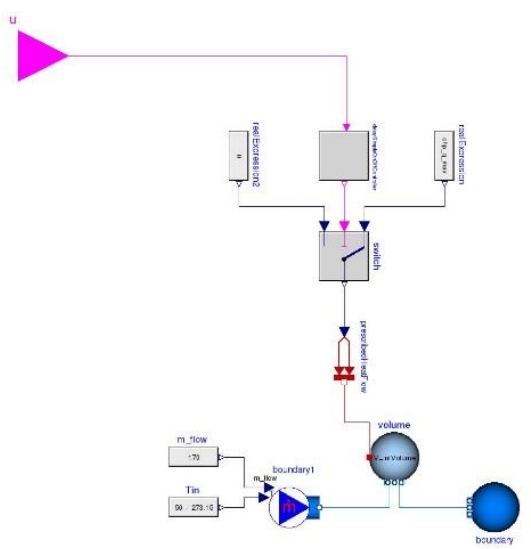

Figure 5: Structure of CHP unit component

\subsubsection{Hot Water Storage}

The main storage component has 2 ports which are input signals; one represents the amount of heat charging while the other is the amount of heat discharged.

Figure 6 shows the structure of the storage component. Obviously, the charging and discharging ports are connected to the water tank. As the heat flow direction is crucial to the discharging process, therefore the discharge value is provided as a negative value.

The water tank component representing the storage tank itself was largely built and developed by Lawrence Berkeley National Laboratory (LBNL) and can be found in the buildings library (Wetter, 2016).

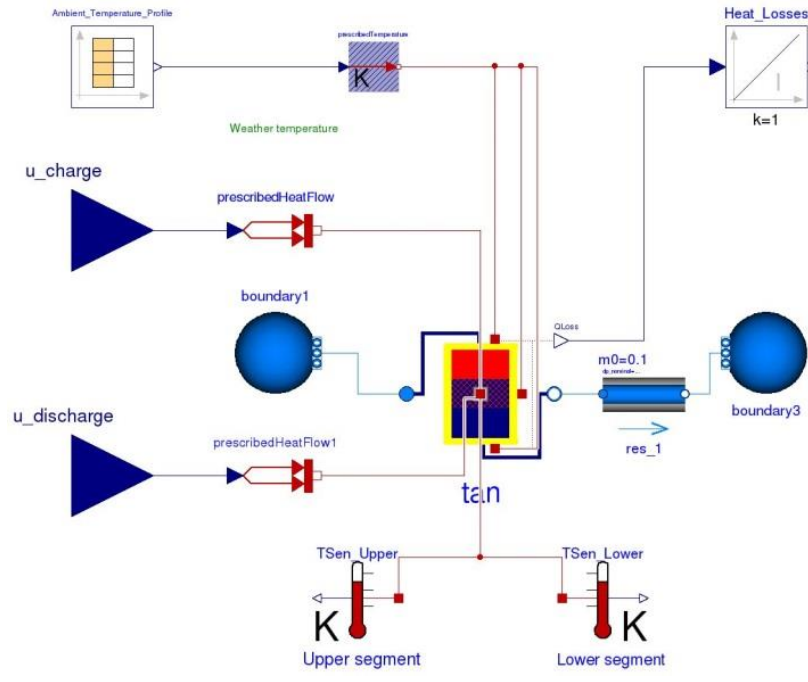

Figure 6: Structure of storage model

The water tank, which is cylindrical in shape, loses heat to the environment due to heat transfer mechanisms arising through the walls of the tank because of the different temperatures. Thus, it is essential to obtain the optimal storage volume by reducing the Surface Area (SA) to its acceptable minimum value and increase the storage volume to the maximum value. Therefore, it is assumed that the tank height is twice its radius, to achieve the minimum SA and maximum volume (Dearling et al., 2006):

$$
\begin{aligned}
& V=2 \pi \cdot r^{2} \cdot h \\
& S A=2 \pi \cdot r^{2}+2 \pi \cdot r \cdot h \\
& h=2 r \rightarrow \max V \text { and } \min S A
\end{aligned}
$$

Due to technical restrictions regarding storage, it is decided to set the minimum temperature in the storage system (maximum temperature at last segment) to $70^{\circ} \mathrm{C}$ and the maximum supply temperature from the storage is set to $100^{\circ} \mathrm{C}$. According to which the thermal storage capacity can be obtained by the following equation:

$$
E=m \int_{T_{1}}^{T_{2}} c_{p}(T) \cdot \mathrm{d} T=m \cdot \overline{c_{p}}(T) \cdot \Delta T
$$

This restriction plays a key role in reducing heat losses from the tank. Heat losses are calculated within the model, taking into account the ambient temperature as Figure 6 shows. Ambient temperatures are given as a measurement and implemented in the system in order to show the real behavior of the storage system. Moreover, "TSen_Lower" component is the temperature sensor for indicating the temperature at lower segment of the tank while "TSen_Upper" is used as an indicator for CHP units to decide whether storage can be discharged or not.

The thermal conductance of the tank is important as it influences the heat losses from the tank. Thus, it is 
calculated in such a way that the influence of the storage medium is excluded. This assumption is true because the impact of the storage medium on the thermal conductivity of the tank is very small. Therefore, the conductance is calculated as below:

$$
G=\frac{k}{L} \cdot S A
$$

The insulation layers of the tank are made of polystyrene which has a thermal conductivity of 0.03 $\mathrm{W} / \mathrm{m} . \mathrm{K}$ with a thickness of $0.1 \mathrm{~m}$ (Terry et al., 2012). Hence, the conductance is automatically calculated as a function of the storage surface area for any given storage volume.

\subsubsection{Boiler}

The boiler component has only two ports, one an input and the other an output. These ports determine the required demand and the supply from the boiler.

Figure 7 shows the configuration of the boiler in Dymola. The boiler input is clearly seen by the port " $u$ " which is the remaining demand, and " $y$ " represents the boiler output. Also, the boiler input is the remaining heat demand after all CHP units run and the storage capacity is discharged.

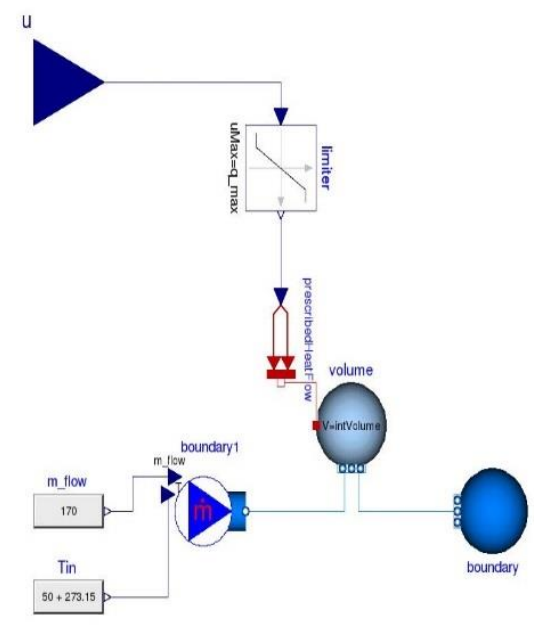

Figure 7: Structure of boiler component

\subsubsection{Central Controlling}

\subsubsection{CHP Controller}

Similar to the real heating station, the bottom segment temperature for storage is set to $70^{\circ} \mathrm{C}$ and the upper one is set to $100^{\circ} \mathrm{C}$. Moreover, for each $\mathrm{CHP}$ unit, an individual CHP controller is installed in the system. In this controller, the heat demand and the storage temperatures (upper and bottom) are simultaneously checked. From Figure 8 , it can be clearly seen that there are 3 cases to run the CHP unit, which are:

1. Power case (a): if the heat demand is higher than the nominal CHP's heat output and the temperature of the bottom segment is higher than $70^{\circ} \mathrm{C}$, then the CHP unit runs.

2. Power case (b): if the heat demand is higher than nominal CHP's heat output and the temperature of the bottom segment is lower than $70^{\circ} \mathrm{C}$, then the CHP unit runs.

3. Power case (c): the CHP unit runs, when the following conditions are all true:

i. The heat demand is lower than nominal CHP's heat output, and

ii. The heat demand is higher than $95 \%$ of the CHP's heat output (equals 1.425 MW), and

iii. The upper storage temperature is lower than $95^{\circ} \mathrm{C}$.

Regarding power case (a), as the storage temperature is equal to or higher than $70^{\circ} \mathrm{C}$, this means the storage can be discharged. On the contrary, if the storage temperature is less than the set bottom temperature $\left(70^{\circ} \mathrm{C}\right)$, this means the energy stored in the storage system cannot be used and, therefore, power case (b) is activated to supply the heat directly to the consumers. While power case (c) is activated in order to cover the heat demand that is higher than $1.425 \mathrm{MW}$ and the remaining of the heat output charges the storage.

Moreover, if the heat demand (or the remaining heat demand for CHP 2-6) is less than 1.425 MW or the upper storage temperature is higher than $95^{\circ} \mathrm{C}$, then the corresponding CHP unit turns off. Moreover, if the bottom storage temperature is set to a constant value (i.e. $70^{\circ} \mathrm{C}$ ), then a strange behavior for CHP units is seen because the CHP unit starts ramping up and down between 0 and the maximum heat output in order to maintain the storage temperature at the exact-desired level. This results in some problems with the modeling. This problem is seen in winter season because the heat demand is high, therefore the storage cannot be charged, and so the temperature cannot be kept above the minimum level. However, keeping the temperature right at a specific temperature is not necessary for the model. Nevertheless, obtaining accurate results for validation is of importance. In order to avoid such problems in modeling, the minimum temperature shall be set in a specific range, so instead of taking a fixed minimum temperature of $70^{\circ} \mathrm{C}$, it is taken between $68^{\circ} \mathrm{C}$ and $70^{\circ} \mathrm{C}$. For this reason, a "hysteresis" component from Modelica standard library (MSL) itself is implemented to solve the above mentioned problem. 


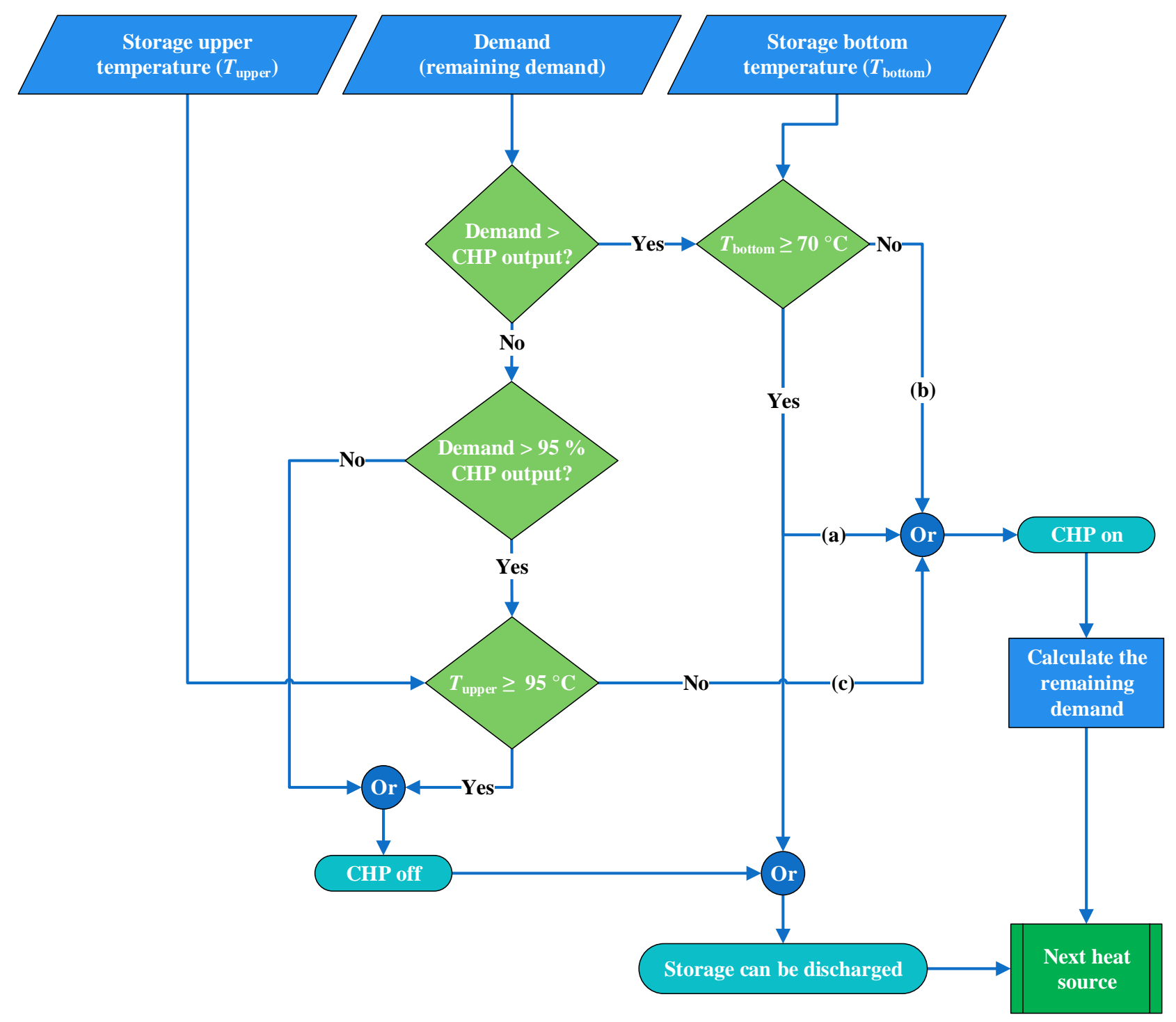

Figure 8: CHP controller flowchart implemented for each chp unit

\subsubsection{Storage Controller}

This controller plays a secondary role in the energy balance of the entire heating station next to the consumer component, since it gives a signal to discharge or charge the storage system. It has 3 input signals and a single output signal. One of the input signals is the storage system temperature at the bottom of the storage tank. Based on the temperature, a decision is made as to whether the storage system can be discharged.

However, if the temperature of storage's bottom is higher than $70^{\circ} \mathrm{C}$, this sends a true signal to the switch component to discharge the storage system to cover the remaining demand. Otherwise the output " $y$ " equals zero when the temperature is less than $70^{\circ} \mathrm{C}$. The remaining demand is given by the following equation:

$$
\dot{Q}_{\text {storage }}=\dot{Q}_{\text {demand }}-\sum_{i=1}^{6} \dot{Q}_{\mathrm{CHP}, i}
$$

Occasionally, the storage system cannot be discharged because the last segment temperature is less than that allowed for discharging, and therefore the remaining heat demand proceeds to the next controller, which is the boiler controller that runs the boiler in order to meet the required amount of heat. 


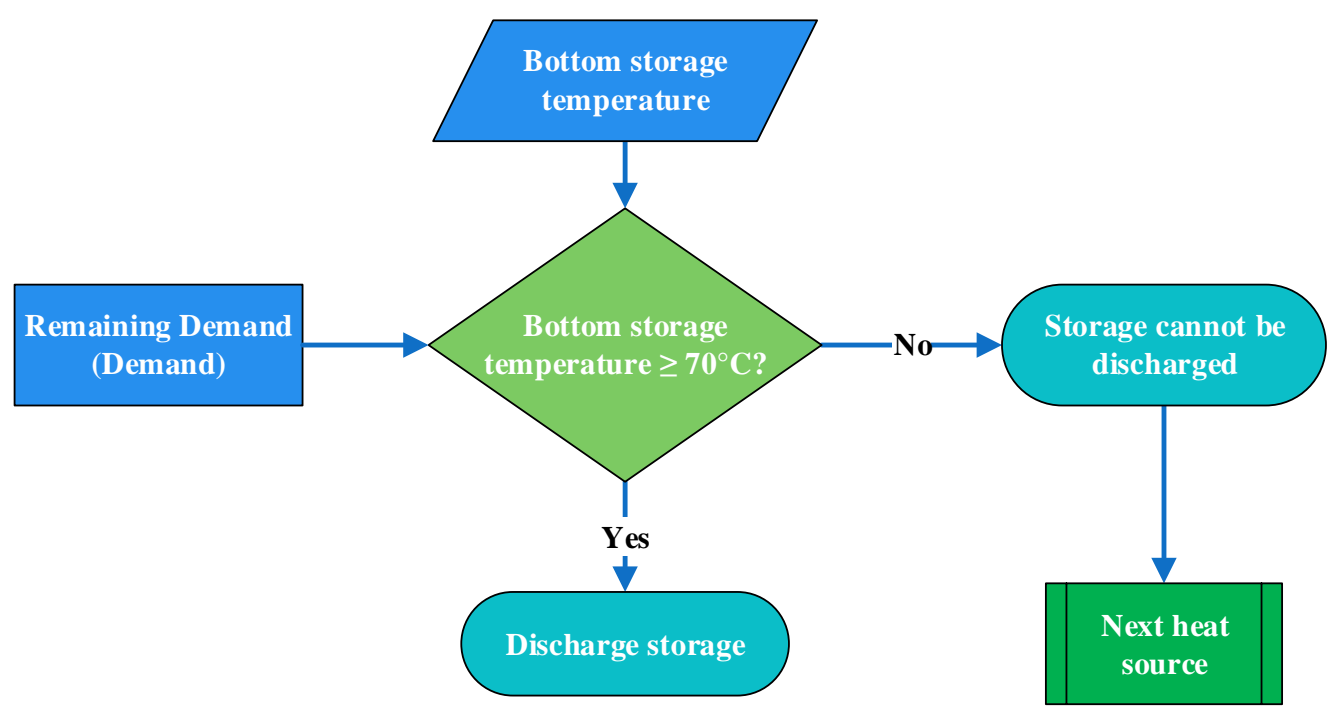

Figure 9: Storage controller flowchart

\subsubsection{Boiler Controller}

The boiler controller is a simple unit which computes how much heat demand remains after the total output of the CHP units and the discharged capacity of the storage system as Figure 10 shows. Next, it gives an output signal to run the boiler in a partial mode to meet the remaining heat demand, thus:

$$
0 \leq \dot{Q}_{\text {boiler }} \leq 27.9 \mathrm{MW}
$$

Here, the remaining demand is computed as below:

$$
\dot{Q}_{\text {boiler }}=\dot{Q}_{\text {demand }}-\sum_{i=1}^{6} \dot{Q}_{\mathrm{CHP}, i}-\dot{Q}_{\text {storage }}
$$

The term $\dot{Q}_{\text {storage }}$ refers to the usable heat in the storage system. Therefore, the usable temperature lies between $70^{\circ} \mathrm{C}$ and $100^{\circ} \mathrm{C}$.

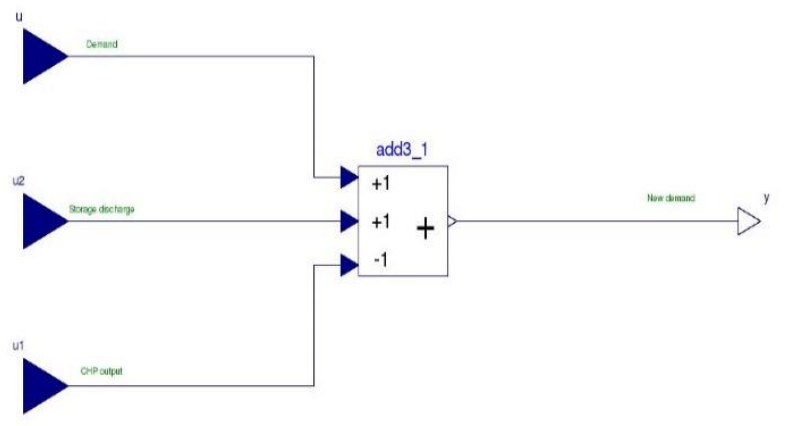

Figure 10: Structure of boiler controller

\section{Validation}

It is held that models with coefficient of determination, $\mathrm{R}^{2} \geq 0.7$ and coefficient of variation of root mean square error (CV-RMSE) $\leq 7 \%$ are arbitrarily deemed to be "good" models (Reddy et al.,
1997). Whilst models with CV-RMSE less than 5\% can be considered excellent models, those with less than $10 \%$ can be considered good models, those with less than $20 \%$ can be taken as mediocre models, and those greater than $20 \%$ are considered poor models (Balci, 1998). However, the constraints that are set in this article for the evaluation of the goodness-of-fit for the model are: $\mathrm{R}^{2} \geq 0.7$ and $\mathrm{CV}-\mathrm{RMSE} \leq 15 \%$. Then it can be said that the model is held to be good.

In validation process, the data sets of the CHP units (both simulated and monitored) are required for validation purposes. This is because the variation between them is important as they are the first heat source that runs in order to meet the heat demand, and they are therefore the most influential parameters, with any disruption in their output having an impact on the other energy systems.

First, the model is visually validated for 9 days of January as a representation of winter season (high heat demand period) as Figure 11 shows.

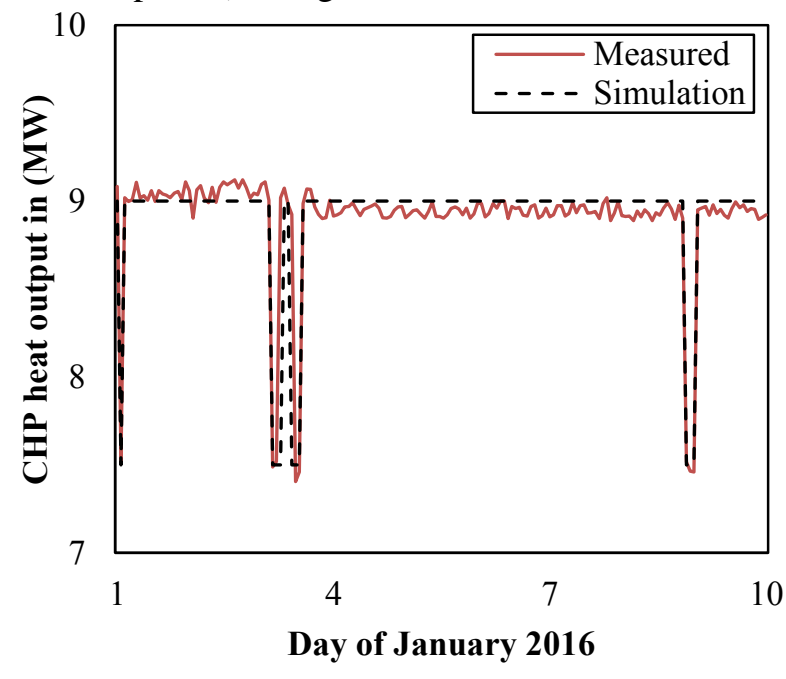

Figure 11: CHP heat output for 9 days of January 2016 
Then numerical validation is performed and the results are as below:

$R^{2}=0.84$

$C V-R M S E=2 \%$

The result of CV-RMSE $=2 \%$ indicates that only this percentage of the real data is not explained by the model.

As the measured data are available for other periods, it is more obvious to validate another period of winter season and, therefore; another 6 days of February (from $5^{\text {th }}$ to $11^{\text {th }}$ of February) are taken to examine the creditability of the model for winter season as shown in Figure 12.

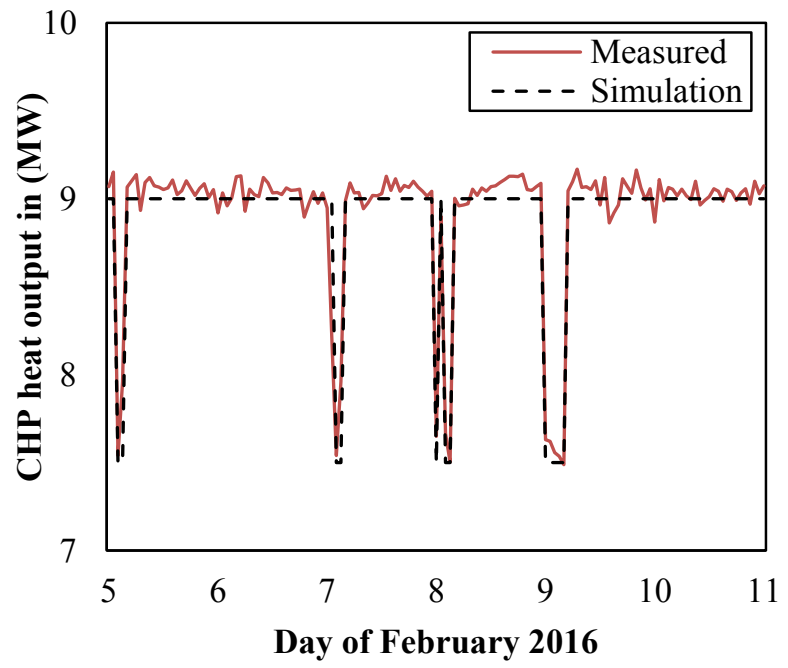

Figure 12: CHP heat output for 6 days of February 2016

The numerical validation results are:

$R^{2}=0.85$

$$
C V-R M S E=2 \%
$$

These results confirm again that the model has a goodness-of-fit in the representation of the actual system and can be used to develop and test control strategies for the heating station. Nevertheless, an uncertainty analysis is crucial after the development in order to investigate the uncertainty percentage in the model for the developments.

Regarding summer season (relatively low heat demand compared to winter), a time series of 7 days out of April 2016 is chosen to evaluate the goodnessof-fit for the model and it is shown in Figure 13. The numerical results are as follows:

$$
\begin{aligned}
& R^{2}=0.87 \\
& C V-R M S E=7 \%
\end{aligned}
$$

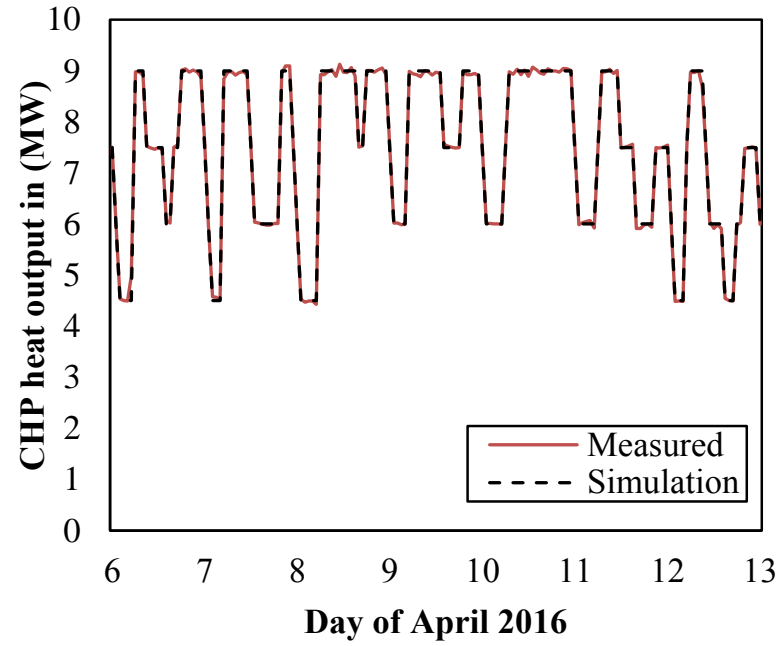

Figure 13: CHP heat output for 7 days of April 2016

For this time period, the $\mathrm{R}^{2}$ value of $0.87(1 \geq 0.87$ $\geq 0.7)$ indicates that the model can represent the real heating station with a good approximation of its real behavior.

As spoken earlier, due to the availability of measured data from the heating station for other periods, it is worthwhile to validate another time series from summer season. Thus, a time series of 5 days is taken from $9^{\text {th }}$ to $14^{\text {th }}$ May 2016 as Figure 14 shows.

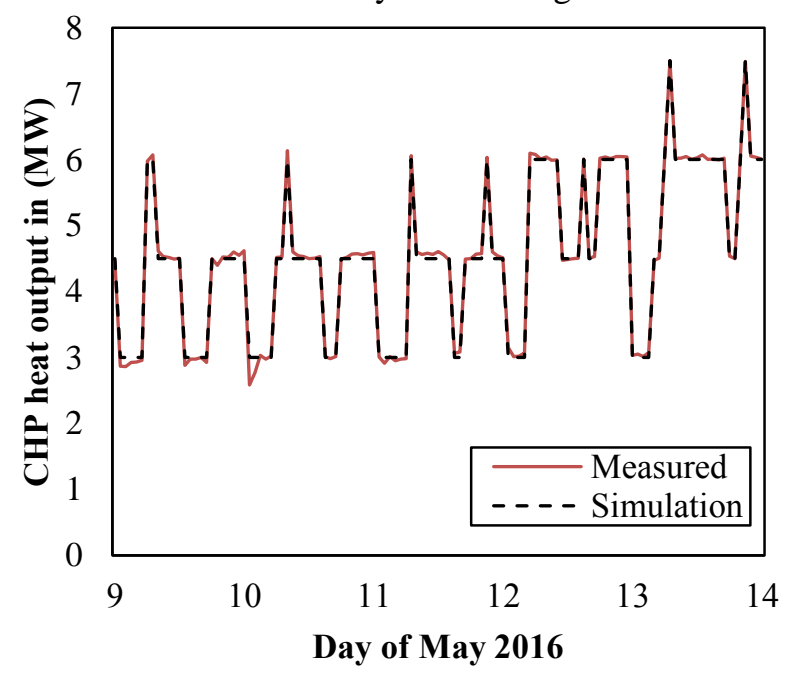

Figure 14: CHP heat output for 5 days of May 2016

Visually, the matching between both series is held to be "good" enough, thus proceeding to numerical validation:

$$
\begin{aligned}
& R^{2}=0.84 \\
& C V-R M S E=7 \%
\end{aligned}
$$

The result of $\mathrm{R}^{2}$ confirms again the goodness-of-fit for the model. While a CV-RMSE value of $7 \%$ indicates that the dispersion of the simulated and real data around the mean of the real data is quite low, and it is therefore clearer that the mathematical model fits the real heating station to a high degree. 


\section{Discussion and Remarks}

The model constructed represents a particularly complex energy-supply system that comprises different energy sources and therefore there is a challenge in terms of energy system modelling and accurate prediction. Any given energy system is characterized by multiple parameters including material properties, casing temperatures and mechanical efficiency of the corresponding energy sources. In addition, there are equipment maintenance schedules, mechanical damage, HVAC and plant operation, real climate and many other parameters to consider. All together, these represent diverse sources for the uncertainty in the model. However, this does not mean that the model cannot fit the actual physical systems to an acceptable degree, but it does lead to a basic requirement to point out the sources of uncertainty.

The various sources of uncertainty in the model can be classified as follows:

1. Specification uncertainty: this kind of uncertainty refers to the physical errors that can arise from incomplete or inaccurate specifications for the complex physical model or process. It may also involve excluding some physical equations or properties, such as the geometry and material properties of the CHP units, boiler and storage system, and the fluctuating efficiency of the CHP units which is taken as constant in the model.

2. Modelling uncertainty: this arises due to the simplifications and assumptions about the complex physical state. It may also involve the exclusion of some energy systems due to their small effect on the model compared to the effort that is required in order to implement them in the model. An example is the exclusion of the CHP casing temperature which has an impact on total CHP efficiency. Moreover, due to the fact that the simulation results are discrete values while the real data are continuous as shown in Figures 11, 12, 13 and 14, this also has an impact on the creditability of the model.

3. Operation uncertainty: this involves external conditions that cannot be integrated into the model constructed because they are unexpected. This is mainly seen in case of damage or other unforeseen effects on the energy conversion chain or system. For instance, the mechanical damage that can occur in the pump or turbocharger of each CHP unit is always unexpected and cannot be predicted.

\section{Conclusion}

This paper presents the modeling process of heating stations for DH system applications using Modelica/Dymola to build a power-based model and then validate it with real data from an existing heating station (Weingarten). Validation results reveal that the goodness-of-fit for the model is considered to be good enough, which permits employing this model for further research work to perform investigations for operational optimization. Furthermore, in (Dahash, 2016), the model is tested for some operational optimization methods and it shows good applicability to be used for power-based optimization methods.

Also, it is worthwhile to clarify that this paper (mainly validation results) does not confirm the applicability of the model with the shown controllers for any existing heating station. It simply reveals that the representation of a specific heating station is held to be good and then it states the sources of uncertainties in the model. Moreover, in order to look for other heating stations, their control strategies should be implemented and adjusted accordingly in the model.

\section{Acknowledgements}

This work is part of the project Weingarten 2020 Monitoring funded by the BMWi (Federal Ministry for Economic Affairs and Energy, Project No.: O3ET2364A). Our thanks go to the operator of Weingarten heating station, Badenova WärmePlus, for the cooperation in the project.

The model described in this article is built as a part of a master thesis supervised by Prof. Dr-Ing. Peter Treffinger and, therefore, the authors wish to thank him for his continuous support.

\section{Nomenclature}

$\begin{array}{clc}\begin{array}{c}\text { Symbol } \\ C V\end{array} & \text { Description } & \text { Unit } \\ -R M S E & \text { Coefficient of variation for } & {[-]} \\ G & \text { Conductance } & {[\mathrm{W} / \mathrm{K}]} \\ h & \text { Height of the storage tank } & {[\mathrm{m}]} \\ k & \text { Thermal conductivity } & {[\mathrm{W} / \mathrm{m} . \mathrm{K}]} \\ L & \text { Thickness of the insulation } & {[\mathrm{m}]} \\ \dot{Q} & \text { Heat flow rate } & {[\mathrm{kW}]} \\ r & \text { Radius of the storage tank } & {[\mathrm{m}]} \\ R^{2} & \text { Coefficient of determination } & {[-]} \\ S A & \text { Surface area } & {\left[\mathrm{m}^{2}\right]} \\ V & \text { Volume of the storage tank } & {\left[\mathrm{m}^{3}\right]}\end{array}$

\section{References}

Bachmaier,A., Narmsara, S., Eggers, J. Bleicke and Herkel, S., 2015. Spatial Distribution of Thermal Energy Storage Systems in Urban Areas Connected to District Heating for Grid Balancing. Energy Procedia, Issue 73, pp. 3-11. 
Balci, O., 1998. Verification, Validation, and Testing. In: J. Banks, ed. Handbook of Simulation: Principles, Methodology, Advances, Applications, and Practice. New York: John Wiley \& Sons, pp. 335-393.

Benonysson, A., Bøhm, B. and Ravn, H.F., 1995. Operational optimization in a district heating system. Energy Conversion and Management, May, 36(5), pp. 297-314.

Braccoa, S., Denticib, G., and Sirib, S., 2013. Economic and environmental optimization model for the design and the operation of a combined heat and power distributed generation system in an urban area. Energy, Volume 55, pp. 1014-1024.

Dahash, A., 2016. A Comparative Study of Modeling Approaches for District Heating Systems, Master thesis, Offenburg-University of Applied Sciences, Offenburg, Germany.

Dearling, C. and Erdman, W.,, 2006. Minimize the Surface Area of a Cylinder . In: Principles of Mathematics 9. 1st ed. Canada: McGraw-Hill, p. 640.

Elci, M., Oliva, A., Herkel, S., Klein, K. and Ripka, A.,, 2015. Grid-interactivity of a Solar Combined Heat and Power District Heating System. Energy Procedia, 5 June, Volume 70, pp. 560-567.

Foschung für die Energieeffiziente Stadt, 2016. Projekt: Modellhafte Stadtquartierssanierung Freiburg Weingarten-West. Available at: $\quad$ http://www.eneffstadt.info/de/pilotprojekte/projekt/details/modellhaftestadtquartierssanierung-freiburg-weingarten-west/

Jie, P., Neng, Z. and Deying L., 2015. Operation optimization of existing district heating systems. Applied Thermal Engineering, 6 January, Volume 78, pp. 278-288.

Joelsson, A. and Gustavsson L., 2008. District heating and energy efficiency in detached houses of differing size. Applied Energy, May.pp. 126-134.

Kelly, S. and Pollitt, M., 2009. Making Combined Heat and Power District Heating (CHP-DH) networks in the United Kingdom economically viable: a comparative approach, s.l.: University of Cambridge.

Nicola Terry, N., Palmer, J. and Cooper, I., 2012. State-of-the-Art Review: Insulation and Thermal Storage Materials, Cambridge, UK: Eclipse Research Consultants.

Olsthoorn, D., Haghighat, F. and Mirzaei, P.A., 2016. Integration of storage and renewable energy into district heating systems: A review of modelling and optimization. Solar Energy, 15 October, Volume 136, pp. 49-64.

Reddy, T. A., Saman, N. F., Claridge, D. E., Haberl, J. S., Turner, W. E. and Chalifoux, A. T., 1997. Baselining Methodology for Facility-Level Monthly Energy Use-Part 1: Theoretical Aspects.

Shipley, A., Hampson, A., Hedman, B., Garland, P., and Bautista, P., 2008. Combined Heat and Power, Effective Energy Solutions for a Sustainable Future, s.l.: Oak Ridge National Laboratory (ORNL).

Smit, R., 2006. Power Quality and Utilisation Guide, s.l.: Copper Development Association.

Wetter, M., 2016. Modelica Library for Building Energy and Control Systems. [Online] Available https://simulationresearch.lbl.gov/modelica [Accessed 14 August 2016]. 